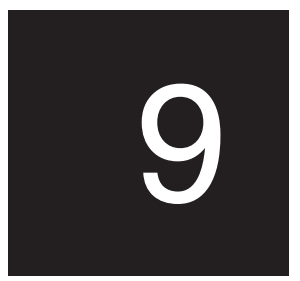

\title{
Fisheries resource-use culture in Fiji and its implications
}

\section{Joeli Veitayaki}

Like other Pacific Islanders, most Fijians are maritime people, with ongoing fishing traditions that are continually retold to the younger generations. Skilled fishers and seafarers are highly regarded. In coastal areas, fish provide an important component of the people's diet, and are of considerable cultural significance. The way in which people use their fishery resources is still influenced to some degree by these cultural factors. Although they may no longer believe literally in all the supernatural aspects involved, or, indeed, slavishly observe all the traditional prohibitions, they are generally aware of them and make reference to their usefulness.

The current consciousness surrounding the significance of traditional fishing practices has made it important that people today understand the culture that was part of traditional resource use. Traditional resource-use practices were based on empirical knowledge of localised natural and cultural systems. Although resource-use methods are rapidly changing, contemporary practices include features that were once part of the traditional system, and these often provide knowledge that can be usefully employed to enhance the sustainable utilisation of fishery resources.

There is an on-going debate as to whether the management practices of traditional fishery resource can be introduced as part of 
contemporary resource management arrangements (Johannes 1978; Hviding 1994; Ruddle 1994; Veitayaki 1995), but it is beyond the scope of this chapter, which is limited to considering how elements of traditional practice influence the contemporary resource-use system. The system of resource-use now observed in many parts of the country is a combination of the traditional system of resource-use and contemporary methods, that take into consideration the changes in Fijian communities. Understanding how the changes in resource use culture takes place and their implications on future fisheries resourceuse will influence the successful implementation of sustainable fisheries development and the effective involvement of local communities.

Coastal communities in Fiji today are undergoing socioeconomic and technological modernisation. Commercial exploitation has given most communities the capability to deplete coastal resources rapidly. With the economic demands to which the people are subjected and their increased capacity and productivity levels, the sustainable use of marine resources has become a major issue. The situation has become so serious that one of the main contemporary challenges is the sustainability of fisheries development projects (Carleton 1983; Johannes 1989; David 1990; Dolman 1990; Liew 1990; Munro and Fakahau 1993). Meanwhile, most coastal fisheries development continues to be characterised by the periodic boom and bust cycles which are associated with the peaks and troughs of trade in marine commodities.

The changes that have taken place in most communities in Fiji call for modern management input. Most traditional communities have not fully understood the environmental issues and the scientific base of inter-relationships in the ecosystem. Science is required to provide information on the nature of the resources and ecosystems. Furthermore, the impact of modern fishing technology on the resource base is important because fishers now have the capability to overfish distant areas where they have never gone before. The increase in the number of fishers makes it critical that every fisher is familiar with the need to keep production levels well within the stock's capacity to replenish itself. The scenario is made more complicated by the deteriorating state of the marine environment.

In some areas of Fiji, the traditional owners of fishing grounds and fishing rights have become passive observers, allowing government officials and external experts to make all the resource-use decisions. In 
these instances, the traditional owners of fishing grounds and fishing rights are instructed in new ways to use their resources. In others, traditional fishing ground and right owners are suspicious of the government's motives because they do not fully understand them. The short lifetime of most fishery development projects, which have been introduced to increase productivity, income-earning opportunities and employment, has often negatively affected the state of the resources and the people's enthusiasm to be part of projects. In some cases, the people are burdened by the failure of projects that were doomed from the beginning because they did not accommodate the sociocultural reality of Fijian communities.

Fishery exploitation in Fiji involves five discrete sectors: subsistence, artisanal, aquaculture, recreational and industrial. The different sectors vary in nature, characteristics and associated issues. Interesting developments are now taking place as coastal Fijian communities are addressing the ecological problems associated with dwindling resources. The people have initiated various attempts to identify more sustainable ways of using their fishery resources and are incorporating traditional and community-based resource-use methods into contemporary arrangements.

\section{Traditional resource-use culture}

The most significant traditional practice still followed in Fiji is the customary ownership of rights to fishing grounds, which extend to the outer reef slope (Iwakiri 1983; Kunatuba 1983; Fong 1994; Waqairatu 1994; Veitayaki 1995). Like land rights, traditional fishing area rights are defined and owned by vanua or tikina (social units that include a number of villages in a district) which regulate their use and exploitation. People are expected to use their own allocations, and those seeking to use grounds belonging to others are expected to get permission from the owners. From time to time fishing ground owners may declare a portion of their grounds out of bounds to preserve the resources for a special purpose such as a wedding, birth or a death ceremony (Ravuvu 1983). On other occasions, the people can place restrictions on fishing methods to protect the resource (Fong 1994).

Traditional management arrangements were embedded in the wider social system, in which traditional authority prevailed, and the systems of retribution ensured compliance. In some parts of Fiji people were killed or banished for serious offences relating to fishing practices (Tippett 1959). The traditional notion of 'sacred ground' is 
still prominent in many parts of Fiji. The sacred fishing grounds were special areas where special rules were strictly adhered to. In such cases 'a close association was perceived between the living and the dead, whose spirits inhabited sacred areas, who showed offence when customary taboos and rituals were not adhered to' (Siwatibau 1984:366). Fishing at such sites was conducted only with the permission of a bete, or traditional priest, or when special requirements were met. In Qoma today, the people going to Cakau Davui, the sacred fishing ground, are expected to obtain special permission, to perform the rituals of an arrival party at the reef, and to fish according to the rules. Among the turtle fishermen of Qoma, the belief is that their gods will provide a catch sufficient for the purpose for which the fishing was asked. The fishers know that once a turtle swims through their net they have caught enough and they will not catch any more. To be successful in their fishing, the people need to please their gods by doing the correct and expected things. In Kaba, the traditional swimming spot for the paramount chief is fished only at the request of the chief.

This association with the supernatural ensures that the 'sacred grounds' are respected and protected at all times, and not only when enforcement officers are around. The supernatural associations can also lead to incidents that seem to defy normal logic and rational thought (Koroi 1989). Fijians accept these special cases because they embody their traditional culture and beliefs. The close ties between the people of Cakaudrove and sharks is one such example. In this part of Fiji, sharks are revered by the people, who in turn are protected by them while at sea. During a trip to one of the islands on the edge of Fiji's Economic Exclusion Zone (EEZ), a naval vessel with the former president and high chief of Cakaudrove on board was caught in a freak storm. At the height of the storm, the listing vessel was propped up by a shark as large as the boat that stationed itself alongside the vessel until the storm passed (Fiji Times, 1 June 1985). In a similar incident, a barracuda which had stationed itself at the Suva Wharf before the Royal yacht Britannia berthed only swam away after the same chief arrived and communicated with it (Sunday Times, 31 October 1982).

On Naigani island, trevally are traditionally fished and eaten according to certain prescribed rules. Fishing is decided by the traditional priest. People would only take home fish sufficient for the day. No fish was to be kept overnight at home, and the unsevered 
bones are returned to the sea in the morning, where they again become a live fish (Veitayaki 1990). In Vanua Balavu, the inland lagoon at Masomo is fished by the community only when the traditional priest authorises it (Koroi 1989). During the fishing, which normally takes around six hours, fishers are not allowed to wear anything other than grass skirts specially made for the occasion. The people should also oil their bodies well. Failure to follow the rules will anger the gods and is a recipe for trouble. Penalties which reflect the severity of the offence are meted out by the spirits.

The thought of retribution by the ever-vigilant gods are a continuous reminder to the people of the need to adhere to tradition, and expected behaviour. The fishing grounds in Fiji, like the land, are associated with the spirits that protected them. Siwatibau explains that in such societies the environment is not something separate 'but an integral part of one's self, providing the physical manifestation of the vital link between the living and the dead' (1984:367). Outsiders, therefore, must observe the protocol and code of conduct in any area they are visiting. For instance, visitors are expected to make an offering to publicise their arrival at a place. This practice ensures that the members of the community are aware of the presence of visitors among them and also protects the visitors from the wrath of the spirits who show offence when customary protocol is not followed (Siwatibau 1984). The tradition also ensures that the customary owners of fishing grounds and rights are consulted every time outsiders want to fish in their area.

Totemic beliefs may also contribute to conservation goals. All Fijians have a plant, a bird and a fish totem (Cappell and Lester 1953; Ravuvu 1983; Veitayaki 1995). The taboo associated with totems restricts particular clans, families, age groups or sexes from catching or eating the species concerned. Exploitation is thus restricted to a certain extent because the fishers are always careful not to harm their totem. In Qoma, for example, the fishers would abandon their nets if their totem fish was caught. Fishing was also a highly specialised activity, carried on by only a relatively few members of the community. This in itself limited the catches and contributed to the general maintenance of stock and the protection of the marine environment. 


\section{The contemporary resource-use culture}

Fiji is presently self-sufficient in fish and earns F\$66.54 million (representing 2.8 per cent of GDP in 1995) through its export of fishery products (Ministry of Agriculture, Fisheries and Forests 1995). The estimated value of the inshore commodities during the same period was around F\$58.32 million. The Fisheries Division has the responsibility for the exploitation and management of all fishery resources, formulating plans for the development of all the various sectors, and monitoring on-going programs. The development of infrastructure and capacity is resulting in a continued increase in the exploitation of inshore resources.

Of the different fishery sectors in Fiji, the industrial sector and the recreational fisheries are predominantly conducted offshore and are associated with high capital inputs. These two sectors are adequately managed and are sufficiently covered in the literature. The development of offshore industrial fishing is beneficial both for the exports that it generates, and the relief that it gives to inshore resources. The inshore fisheries consist of subsistence, artisanal, commercial sectors and aquaculture that are mostly small-scale and operated cheaply by local people. Variations within the inshore fisheries are evident in spite of the use of the same resource base.

Since the establishment of the Fiji Fisheries Division in 1968, the national five year plans have emphasised the development of smallscale artisanal fishery through the introduction of new, motorised fishing boats, improved fishing gear and methods, the processing of traditional export items, the establishment of marketing and transportation systems, ice-making and cold storage plants, and the improvement of landing and berthing facilities in the main fishing centres.

The developments taking place in the management of inshore resources illustrate the incorporation of traditional practices into contemporary resource-use arrangements. The government, for instance, has recorded, surveyed and registered customary fishing ground boundaries that were previously based on oral claims. Some 406 customary fishing grounds have already been established. The government has involved the customary owners in the award of 
commercial fishing licenses within their areas (Kunatuba 1983; Cavuilati 1994), and is planning to return to the communities the ownership of their traditional fishing grounds, which currently rest with the state, a direct result of Fiji's colonial experience (Waqairatu 1994).

Commercial fishers operating within customary fishing areas in Fiji are required by law to have a licence which is renewable every year (Ministry of Agriculture Fisheries and Forests 1994; 1995). The licences are not transferable and are issued by the Fisheries Division on receipt of the approval of the head of the customary units owning the fishing area. Fishers seeking fishing licenses within the customary fishing areas are expected to pay goodwill money. Though open to abuse, this system effectively restricts the number of users in any customary fishing area and removes open access conditions. Fishing licenses offered in this way, although not rationally decided upon (as the traditional owners offer their consent to nearly everyone who asks and pays for them), can be improved if some scientific basis for permit allocation is used.

It is government policy that the customary fishing areas (inside demarcated area-IDA) be reserved as much as possible for local owners and other residents. The Fisheries Division is thus encouraging commercial fishing operators to go to outside demarcated areas (ODA) and exploit resources in those areas that are not traditionally important to people. The government's intention to develop specific ODA sectors are well illustrated by the placement of Fish Aggregation Devices (FADs) and the promotion of half cabin FAO-designed fishing boats; both of which enhance the movement away from the exploitation of inshore fisheries.

There are other examples that illustrate the incorporation of traditional and community-based marine resources management systems in Fiji. In Kaba Point the people, who were fed up with poorly planned fishery projects that they had been part of, decided that any future marine-based development, involving the use of their coastal resources within their customary fishing areas, required thorough evaluation (Veitayaki et al. 1996). They invited researchers from the local university and government to scientifically assess the viability of their proposed fisheries project. The study findings indicated that local fishery resources were extensively used and that further intensification of current fishing practices could not be viable. As a result of the study the villagers are redefining their goals and options for using and managing their coastal resources. 
In a related development, the people approached their paramount chief and briefed her on the disturbed natural situation. The chief responded by initiating a six month ban on gillnet fishing within the Kaba Point areas. In 1995, the chief decided not to renew the seventeen permits for the commercial fishers within their customary fishing grounds and to restrict fishing to only the people of Kaba Point for a year. In May 1996, the villagers hosted a marine awareness workshop where they invited government representatives, non-government organisations and researchers to discuss the management of their coastal resources. The villagers are now pursing other alternatives such as aquaculture and deep-sea fishing to allow for the recovery of their fishing grounds. The people of Kaba Point are aware of the issues facing them and are using the opportunities available through traditional management arrangements to address them.

Similar developments are taking place in other parts of Fiji as customary fishing ground owners determine the exploitation of their resources. In Lau, the paramount chief of the province in the late 1980s banned the commercial exploitation of fisheries in his domain. According to the chief, commercial fishing makes a mockery of customary fishing tenure and therefore promotes a system of marine resource use that is detrimental to people and the proper utilisation of fishery resources (Veitayaki 1990).

In Verata, Tailevu, the people have banned the use of driftnets in their customary fishing grounds for about two years now. This decision was taken by the owners of the customary fishing area after observing the deteriorating status of their fisheries. A year after the moratorium on gillnet fishing, there was much celebration when the big fish that the people claimed to have missed for years returned to the fishing grounds. The chief and the people of Verata have decided to extend the moratorium and are thinking of making the ban a permanent management arrangement. A similar arrangement is being observed within Macuata in Vanua Levu, where the chiefs have testified to the value of a moratorium on gillnet fishing, huka gear use and Sunday fishing (Fong 1994).

In some other parts of Fiji, customary fishing ground owners have refused the building of roads and the use of coastal resources by tourists because of the pressure on fishery resources. The chief and people of Kiuva, Tailevu, for instance, have repeatedly opposed the construction of a road to their village because it would involve clearing and draining extensive mangrove areas on their land. The 
mangrove areas provide the people's main fishery resources. According to the chief and the people of Kiuva, it is better to travel by punts and have a good productive fishery than to travel by road and be left with badly destroyed resources.

On many occasions the owners of customary fishing areas have confronted fishers and tourist operators they believed were abusing their coastal resources. Although this situation is not conducive to the economic reputation of the country, it shows that the owners of customary fishing areas are serious about the proper use of their coastal resources. In some instances, fishing gear has been destroyed and lives threatened as customary owners exert control within their areas.

In some parts of Fiji, owners of customary fishing areas have employed fish wardens to patrol their territory. These people undertake surveillance work within their customary areas on behalf of the owners of customary fishing areas and the Fisheries Division. Although fish wardens are not paid, their involvement illustrates the commitment of coastal communities to the proper use of their customary fishing areas.

There is an increasing interest throughout Fiji in the declaration and development of marine reserves and protected areas. This is a direct result of the deteriorating state of fisheries, public education initiatives, and the realisation that a great deal of money can be earned through the display of properly managed marine environments and fishery resources. The development of protected marine areas and reserves in Fiji will be easy, as the ownership of the customary fishing areas is already held by the people, who only need to agree as a group to have a portion of their fishing ground declared a marine reserve or protected area. In some districts such as Tacilevu in Savusavu on Vanua Levu, the people have decided to prohibit fishing at all times in some portion of their fishing grounds. Fish do not respect humandrawn boundaries and so the effects of the fishing ban on a portion of the fishery is expected to have a positive influence on the whole fishery. The lifting of the prohibition period on a given portion of the fishing ground is decided on by the people depending on the feedback received by the fishers. Once a prohibited area is opened another portion is closed to all fishing. According to the people, they are enjoying good catches and are happy with their arrangements. 
In collaboration with government departments and some nongovernment organisations, such as the Fiji Dive Operators Association, the International Ocean Institute, the World Wide Fund and the University of the South Pacific, some owners of customary fishing areas are participating in marine public education workshops to educate people who use the fisheries to consider the impact of their activities and to appreciate the importance of having a healthy, productive and vibrant marine environment. Judging from the current interest in these workshops the message appears to be getting through and is being well received by people.

\section{Issues of fisheries resource-use culture}

Although the traditional system of resource use was formulated for a time long gone, contemporary experience in Fiji has shown the usefulness of some traditional practices. Customary Marine Tenure and the involvement of customary ground owners in the management of fishery resources today, illustrate the amicable amalgamation of the two systems. In addition, some of the activities of those involved in fishery resource management are possible only because of the traditional rights people have over fishery resources. The traditional ownership of fishing areas, for instance, alleviates most of the problems associated with open access. On the other hand, custom is often quoted as a reason why people are still having difficulty managing their fishery business.

The development of fishery resources is a major undertaking because of the importance of fish to people and the significance of the marine environment. The uncertainties within the marine environment require that careful planning be conducted to ensure the amicable development of all sectors. An emphasis on maximising production and development should be pursued cautiously because of the need to ensure that resources are sustainably exploited and that the environment is not overly degraded. Other users of the sea should be consulted so that they are included in management decisions to conserve the resources and the marine environment.

Major contemporary fishery development issues are associated with the increasing commercial exploitation of the resources and the continued degradation of the marine environment. The major issues 
associated with the commercial exploitation of inshore fisheries include: the successful development of small-scale or artisanal fisheries; the management of fisheries and fishing grounds; the use of appropriate fishing technology; the importance of fish and fishing income; marketing and the distribution systems; uncertainty over what constitutes the resource, and the loss of traditional management practices.

Issues relating to the degradation of the marine environment include: the changing availability of fishery stock; the difficulties of conducting resource assessments, changes in environmental conditions, pollution and the pressures of land based activities.

The sustainable utilisation of fisheries in the future will depend on how well these issues are addressed. The present low number of successful fishery projects seems to indicate our failure to find the magical formula. The fact that the technology or the capital is available from an external source should not be allowed to drive the development of fisheries.

\section{Future implications}

Challenging times are facing nations like Fiji, which are attempting to develop their fishery resources for maximum benefit while undertaking to ensure their sustainability. The transition from subsistence to commercial and industrial fishery exploitation places more stress on the fisheries. The increasing number of fishers and their greater capacity will make the situation acute. Although the development of deep sea fisheries may help to reduce the intensity of fishing in inshore areas, the dominance of foreign interests in the exploitation of resources in the sector is cause for concern. It is unlikely that Fijian interests will dominate in this sector within the foreseeable future. There is a need for education to promote the importance of exploiting the resource in a manner that will enable future generations to enjoy the same resource that we are exploiting today.

The task of sustainable fishery management is made more difficult by the fact that the marine environment is being changed by the impacts of human activities and the reduced fish biomass. The preferential fishing demanded by the market places some species at greater risk. In addition, the impact of depleted fisheries on the ecosystem generally is uncertain. Thus the resources, their range and their nature are little known to people who are trying to manage them 
(Veitayaki and South 1993; Slatter 1994). The figures used for management are approximations based on what people hope are reasonable assumptions and estimations. In the meantime, the business-as-usual approach continues in the hope that the current exploitation levels are within the capacity of the stocks to limit the impact of fishing.

The industrial fishery development in offshore areas is especially welcomed in Fiji because of the opportunities it provides to food provision and income earning. Offshore resources provide useful alternatives to intensively exploited inshore resources. The difficulty of establishing local markets for offshore fishery products and the problems associated with the need to extend fishing to offshore areas are related to traditional fishery resource-use customs. Unlike inshore areas, the offshore is open and the government is responsible for the management and control of all activities outside of customary fishing areas and extending outward to the edge of Fiji's EEZ. In these areas, enforcement of legislation is a necessary but costly exercise.

Maximum production is not the only way of attaining maximum gain. Improving post-harvest treatment and processing can enable people to maximise their gain and simultaneously protect their resource base by encouraging people to catch fewer fish and thus cause less disturbance to the marine environment. Reducing postharvest loss is an aspect of contemporary fishing which is new to Fijian communities. Fijians traditionally did little of the processing they are now required to do by the commercial fishing in which they are involved.

The loss of traditional management arrangements currently experienced in Fiji is linked to the social changes taking place in traditional communities. Although the systems of resource-use of traditional communities are appropriate and effective, they have been quickly eroded and replaced by modern systems. There is a serious dilemma now in trying to save what is known of these rapidly changing systems of resource use. Current experience is showing how the useful elements of traditional resource use systems can be put to good use. The Customary Marine Tenure system for example, is a traditional management arrangement that is addressing the issues of open access characteristic most contemporary fisheries.

It is critical to understand fully the sociocultural situation affecting fishery use. Often, fishery projects that are planned elsewhere are imposed on people whose system of doing things is not well 
understood by those planning the projects. The lack of consistency among Fijian fishers in villages, the cultural factors that hinder commercial fishery operations and the people's lack of interest in certain fisheries are all related to traditional customs. Fijians need to be trained in marketing skills and fishery valuation.

Marine reserves and protected areas should be encouraged because of poor knowledge about marine habitats and organisms. Fishery resource management at the community level provides a workable unit for implementing this management concept. The chances of success will be better if the necessary scientific knowledge is made part of the system. The customary fishing areas are part of the people's heritage which they will need to manage.

A good system of education is required to improve the management of fishery resources. Modern scientific knowledge and data collection methods need to be disseminated through an effective education program that targets not only schools but all categories of users. Public education is as important as the development of curriculum for schools and tertiary education institutions. The proper use of fishery resources will demand commitment from all people and a good education system should be used to mobilise community support. Education is also critical to the acceptance of rational fishing in line with sustainable fishery use.

The traditional culture of fishery resource use is important to the sustainable utilisation of fishery resources in the future and should be taken into consideration when fishery developments are being planned. It is important to involve local communities in sustainable fishery development and to convince them through the use of good education programs. Fishery resources are important to the people and should be utilised in a manner that enables the people to enjoy the use of these resources now and in the future. For this purpose, Fijians need to employ all available fishery resource use culture to draw up effective methods for contemporary resource use; methods that allow maximum benefit and at the same time protect the resource base.

\section{References}

Cappell, A. and Lester, R.H., 1953. 'The nature of Fijian totemism', Fiji Society of Science and Industry, 2(1-5):59-67.

Carleton, C., 1983. Guidelines for Establishment and Management of Collection, Handling, Processing and Marketing Facilities for the 
Artisanal Fisheries Sector in the South Pacific Commission Area, SPC/ Fisheries 15/WP.6, Noumea.

Cavuilati, S.T., 1993. 'Managing fisheries resources: the Fiji experience', in G.R. South (ed.), Marine Resources and Development, Pacific Islands Marine Resources Information System, Suva:35-62.

David, G., 1990. Strategies of reef resources exploitation in Pacific islands, the case of Vanuatu, in Proceedings: International Society of Reef Studies Congress, Noumea (unpublished).

Dolman, A.J., 1990. 'The potential contribution of marine resources to sustainable development in small island developing countries', in W. Beller, P. d'Ayala and P. Hein (eds), Sustainable Development and Environmental Management of Small Islands, UNESCO and Parthenon Publishing Group, Paris:87-102.

Fong, G., 1994. Case study of traditional marine management system: Sasa village, Macuata Province, Fiji, Field Report 94/1, Forum Fisheries Agency, Food and Agriculture Organisation, Paris.

Hviding, E., 1994. 'Customary marine tenure and fisheries management: some challenges, prospects and experiences', in G.R. South, D. Goulet, S. Tuqiri and M. Church (eds), Traditional Marine Tenure and Sustainable Management of Marine Resources in Asia and the Pacific, International Ocean Institute-South Pacific, Suva:88-100.

Iwakiri, S., 1983. Mataqali of the sea: a study of the customary right on reef and lagoon in Fiji, the South Pacific, Kagoshima University, Kagoshima.

Johannes, R.E., 1978. 'Traditional marine conservation methods in Oceania and their demise', Annual Reviews Ecological Systems 9:349364.

— 1989. 'Managing small-scale fisheries in Oceania: unusual constraints and opportunities', in H. Campbell, K. Menz and G. Waugh (eds), Economics of Fishery Management in the Pacific Islands Region, Proceedings of an international conference held at Hobart, Tasmania, 20-22 March 1990, Australian Centre for International Agricultural Research, Canberra:85-93.

Koroi, M., 1989. 'The sacred fish of Masomo', Fiji Times, January 28.

Kunatuba, P., 1983. A report on the traditional fisheries of Fiji, Institute of Marine Resources Technical Report, Suva.

Liew, J., 1990. 'Sustainable development and environmental management of atolls', in W. Beller, P. d'Ayala and P. Hein, Sustainable Development and Environmental Management of Small Islands, UNESCO and Parthenon Publishing Group, Paris: 77-86. 
Ministry of Agriculture, Fisheries and Forests, 1994. Fisheries Division Annual Report, Suva.

— 1995. Fisheries Division Annual Report, Suva.

Munro, J.L. and Fakahau, S.T., 1993. 'Appraisal, assessment and monitoring of small-scale coastal fisheries in the South Pacific', in A. Wright and L. Hills (eds), Nearshore Marine Resources of the South Pacific. Information for Fisheries Development and Management, Institute of Pacific Studies, Forum Fisheries Agency and International Centre for Ocean Development, Suva:15-54.

Ravuvu, A. 1983. Vaka i taukei: the Fijian way of life, Institute of Pacific Studies, Suva.

Ruddle, K., 1994. 'Traditional marine tenure in the 90s', in G.R. South, D. Goulet, S. Tuqiri and M. Church (eds), Traditional Marine Tenure and Sustainable Management of Marine Resources in Asia and the Pacific, International Ocean Institute-South Pacific, Suva:6-45.

Siwatibau, S., 1984. 'Traditional environment practices in the South Pacific-A case study of Fiji', Ambio, 13 (5-6):365-68.

Slatter, C., 1994. 'Food or foreign exchange? regional interests versus global imperatives in pacific fisheries development', in A.Emberson-Bain (ed.), Sustainable Development or Malignant Growth. Perspectives of Pacific Island Women, Marama Publications, Suva:123-30.

Tippett, A.R., 1959. 'The survival of an ancient custom relative to the pig's head, Bau, Fiji', The Fiji Society, 6(1-2):30-39.

Veitayaki, J., 1990. Village level fishing in Fiji: a case study of Qoma island, MA Thesis, University of the South Pacific.

1995. Fisheries Development in Fiji: The quest for sustainability, Ocean Resources Management Program, Institute of Pacific Studies, Suva.

Veitayaki, J. and South G.R., 1993. Inshore fisheries in the tropical South Pacific - a question of sustainability, Paper presented at the 1993 Fisheries and Environment Beyond 2000 International Conference at the Universiti Pertainian, Malaysia (unpublished).

Veitayaki, J., Bidesi, V.R., Matthews, E. and Ballou, A. (eds), 1996. Preliminary Baseline Survey of Marine Resources of Kaba Point, Fiji, USP Marine Studies Technical Report 96/1, Suva.

Waqairatu, S., 1994. 'The delimitation of traditional fishing groundsthe Fiji experience', in G.R. South, D. Goulet, S. Tuqiri and M. Church (eds), Traditional Marine Tenure and Sustainable Development in Asia and the Pacific, International Ocean Institute-South Pacific, Suva:79-84. 